\title{
Association of hematological indices with prediabetes: A cross-sectional study
}

\author{
Amir Ziaee ${ }^{1}$, Azam Ghorbani ${ }^{2}$, Saied Kalbasi ${ }^{3}$, Alireza Hejrati ${ }^{4}$, Saba Moradi ${ }^{5}$
}

\begin{abstract}
${ }^{1}$ M.D., Endocrinologist, Professor, Pediatric Growth and Development Research Center, Institute of Endocrinology and Metabolism, Iran University of Medical Sciences, Tehran, Iran

${ }^{2}$ M.Sc., MSN, of Nursing Education, Faculty Member, Metabolic Diseases Research Center, Qazvin University of Medical Sciences, Qazvin, Iran

${ }^{3}$ M.D., Endocrinologist, Associate Professor, Department of Endocrinology, Loghman Hospital, Shahid Beheshti University of Medical Sciences, Tehran, Iran

${ }^{4}$ M.D., Endocrinologist, Assistant Professor, Department of Endocrinology, Rasoul Akram Hospital, Iran University of Medical Sciences, Tehran, Iran

${ }^{5}$ MD., General Practitioner, Tehran, Iran
\end{abstract}

Type of article: Original

\begin{abstract}
Background: Prediabetes is a condition that occurs when blood glucose levels are higher than normal, but not high enough to be classified as diabetes. Prediabetic people have an increased risk of developing type 2 diabetes and cardiovascular disease. Moreover Hyperglycemia has multiple effects on the hematological parameters.

Objective: To examine the association between hematological indices and anthropometric measurement, with prediabetes.

Methods: This cross-sectional study was conducted on 125 diabetics and 259 prediabetics in the 20-70 age range. They were selected by a convenience sampling method at the Taban Diabetes Center in 2015. An oral glucose tolerance test was performed for each participant who had never been diagnosed with diabetes. Participants were characterized as having prediabetes or diabetes according to American Diabetes Association criteria. The hematologic parameters were measured by using Sysmex-KX 21N analyzers. Data were analyzed by IBM-SPSS version 22 using independent-samples t-test, Mann-Whitney U test, and Pearson's correlation coefficient at $\mathrm{p}<0.05$.

Results: There was significant difference in mean corpuscular hemoglobin concentration (MCVH) (33.81 \pm 0.92 $\mathrm{g} / \mathrm{dL}$ vs. $34.06 \pm 1.05 \mathrm{~g} / \mathrm{dL}$ ) between prediabetes patients and diabetes. There was not a statistically significant difference in the prediabetics' hematological parameters, compared with the diabetics. In the prediabetic group, only the mean corpuscular hemoglobin concentration was found to be negatively correlated with diastolic blood pressure $(\mathrm{p}=0.013)$ and FBS $(\mathrm{p}=0.026)$.

Conclusion: Hematological indices are important markers for the assessment of variations in size, number, and maturity of different blood cells. Hematological indices could be utile indicators of vascular complication and glycemic control in type $2 \mathrm{DM}$ patients. Thus, they are important for the evaluation and early management of patients with per diabetes.
\end{abstract}

Keywords: Prediabetes, Blood Cells, Leukocytes, Erythrocytes, Diabetes Mellitus

\section{Introduction}

Diabetes mellitus (DM) is a complicated metabolic disease and now one of the most important communal health problems in the world (1). In patients with chronic hyperglycemia, numerous cellular components of blood are damaged, which causes several microvascular complications (2). Whereas these vascular complications of diabetes are among the main causes of morbidity and mortality (3), it should be noted that so many pathophysiological

\section{Corresponding author:}

Azam Ghorbani, Metabolic Diseases Research Center, Qazvin University of Medical Sciences, Qazvin, Iran.

Tel: +98.2833360084, Fax: +98-28333260339, Email: ghorbani_az@yahoo.com

Received: January 30, 2017, Accepted: August 05, 2017, Published: September 2017

iThenticate screening: June 13, 3017, English editing: September 06, 2017, Quality control: September 12, 2017

This article has been reviewed / commented by three experts

(C) 2017 The Authors. This is an open access article under the terms of the Creative Commons Attribution-NonCommercialNoDerivs License, which permits use and distribution in any medium, provided the original work is properly cited, the use is non-commercial and no modifications or adaptations are made. 
disturbances have resulted in the development of diabetic microangiopathy, including impaired hematological indices. In DM, hematological indices such as WBC count, Hct count, platelet count, erythrocyte aggregation, and erythrocyte deformability, are disturbed, which can lead to the development of inflammation and a tendency for coagulation and microvascular complications (4). Nevertheless, the association of hematological parameters and prediabetes is not well understood. A previous study demonstrated that people with impaired fasting glucose (IFG) and impaired glucose tolerance (IGT), i.e. prediabetes, had a greater chance of developing diabetes after 5-10 years (5). Furthermore, in the Framingham Heart Study, Levitzky et al. reported that women with IFG were more at risk of developing coronary heart disease (CHD) than men with it (6). Patients with T2DM have an increased risk of atherogenic dyslipidemia and cardiovascular disease (CVD) and the enhanced blood viscosity adversely affects the microcirculationin diabetes patients, leading to micro angiopathy (7). Also, increased levels of hematocrit and blood viscosity contributes to the development of insulin resistance and are independent predictors of type 2 diabetes (8). Some articles have documented that the hematological disorders, such as whole blood viscosity, erythrocyte deformability, and aggregation, are examined in the context of elevated blood glucose level in type 2 DM $(9,10)$. However, a few prior studies surveyed association between hematological parameters and prediabetes and showed increased red cell count (11) and leukocyte count (12). Also, increased platelet activation (13) is related to prediabetic states. It has not been clear whether hematological indices were affected at or the onset of diabetes in the prediabetes period. Hematological indices are valuable indicators for the evaluation changes of different blood cells. They are important for the recognition, care and management of patients with DM. Therefore, this study aimed to investigate the association between prediabetes and hematological indices in Tehran, Iran.

\section{Material and Methods}

This cross-sectional study was carried out on 384 participants with glucose metabolism disorders (125 diabetics and 259 prediabetics). They were in the 20 to 70 age range and had referred to the Taban Diabetes Center in Tehran, Iran, from September 2015 through April 2016. They were selected using a convenience sampling method. The Ethics Committee of Iran University of Medical Sciences approved the study. After introducing the study to the participants and getting informed consent from them, sociodemographic data were collected by well-trained physicians at the Taban Diabetes Center. Their weight and height were measured with a standard method. The body mass index (BMI) was calculated on the basis of the following formula: bodyweight in kilograms divided by height in meters squared (14). The subjects' plasma glucose level was measured after 12-14 hours' fasting in a specific laboratory. An oral glucose tolerance test (OGTT), using $75 \mathrm{~g}$ of glucose, was performed on subjects without a history of diabetes. According to the American Diabetes Association (ADA) classification (15), impaired fasting glucose (IFG) was defined as fasting plasma glucose (FPG) between 100-125 mg/dL and impaired glucose tolerance (IGT) was defined as the 2 -h value in the OGTT $\geq 200 \mathrm{mg} / \mathrm{dL}$. However, diabetes was defined as one of the following: FPG $\geq 125 \mathrm{mg} / \mathrm{dL}$, 2-h post-load glucose $\geq 200 \mathrm{mg} / \mathrm{dL}$ during an OGTT, previously diagnosed diabetes, or the regular consumption of oral medication or insulin. IFG and IGT were considered prediabetes. The study population was divided into two groups, namely, subjects with diabetes and those with prediabetes. The subjects with the following known hematologic diseases were excluded from the study: anemia, pregnancy, thyroid disorders, cirrhosis, renal anemia, and any condition that could affect blood cells. Blood pressure (BP) in both arms was measured in the sitting position within five minutes by well-trained personnel using an analog sphygmomanometer. The average of the two measurements was used for a final BP analysis. Two milliliters of venous blood was drawn from each participant's antecubital vein in the sitting position and collected in a test tube containing Ethylenediaminetetraacetic acid (EDTA) anticoagulant with the aim of evaluating hematological parameters, i.e. mean corpuscular volume (MCV), mean corpuscular hemoglobin $(\mathrm{MCH})$, mean corpuscular hemoglobin concentration (MCHC), red cell distribution width (RDW), white blood cell (WBC) count, red blood cell (RBC) count, hemoglobin (Hgb) count, platelet count, hematocrit (Hct) count, and neutrophil count. Hematological parameters were determined by impedance measurements (Coulter ${ }^{\circ}$ LH 780, Beckman Coulter $\mathrm{GmbH}$, Krefeld) (16). Descriptive statistics such as frequency, mean, and standard deviation were applied. Data with abnormal distribution have been reported as median and interquartile. An independent-samples t-test and the MannWhitney U-test were used for comparing normally distributed data and normally distributed data variables. The association between the variables was assessed using Pearson's correlation coefficient. A P-value less than 0.05 was considered statistically significant.

\section{Results}

A total of 384 participants (125 diabetics and 259 prediabetics) entered the study. Mean age was $44.80 \pm 9.43$ years; Subjects with prediabetes were younger than diabetes subjects $(43.78 \pm 9.45$ versus $46.89 \pm 9.08$; $\mathrm{p}<0.002)$. The majority of the prediabetics were male $(n=152$, i.e. $58.7 \%)$ and the majority of the diabetics were female $(n=76$, i.e. 
60. 8\%). The only significant difference for female participants with prediabetes compared with participants with diabetes was in the MCHC ( $\mathrm{p}=0.046)$. The median and interquartile of the MCV, BMI, Hgb, Hct, MCH, and FBS revealed that there was not a statistically significant difference between the two groups in both genders (Table 1).

Table 1. Demographic, hematological indices and clinical characteristic of the study participants

\begin{tabular}{|c|c|c|c|c|c|c|c|c|}
\hline \multirow{2}{*}{\multicolumn{2}{|c|}{ Variables }} & \multirow[t]{2}{*}{ Total } & \multicolumn{2}{|l|}{ Men } & \multirow[t]{2}{*}{ p-value } & \multicolumn{2}{|l|}{ Women } & \multirow[t]{2}{*}{ p-value } \\
\hline & & & $\begin{array}{l}\text { Subjects with } \\
\text { Pre Diabetes }\end{array}$ & $\begin{array}{l}\text { Subjects with } \\
\text { T2 Diabetes }\end{array}$ & & $\begin{array}{l}\text { Subjects with } \\
\text { Pre Diabetes }\end{array}$ & $\begin{array}{l}\text { Subjects with } \\
\text { T2 Diabetes }\end{array}$ & \\
\hline \multicolumn{2}{|l|}{ Age (year) ${ }^{b}$} & $44.80 \pm 9.43$ & $44.52 \pm 9.83$ & $48.46 \pm 7.30$ & $0.003^{\mathrm{a}^{*}}$ & $42.70 \pm 8.80$ & $45.88 \pm 9.97$ & $0.025^{\mathrm{a}^{*}}$ \\
\hline \multicolumn{2}{|c|}{ Male/Female; $n(\%)^{\mathrm{c}}$} & $\begin{array}{l}201(52.3) / 183 \\
(47.7)\end{array}$ & $152(75.6)$ & $49(24.4)$ & - & $107(58.5)$ & $76(41.5)$ & $<0.001^{\mathrm{a}^{*}}$ \\
\hline \multirow[t]{3}{*}{ WBC indices } & $\begin{array}{l}\text { WBC }\left(10^{3} / \mu \mathrm{L}\right) \text { median } \\
\text { (interquartile range) }^{\mathrm{a}}\end{array}$ & $6.5(5.5,7.6)$ & $6.4(5.4,7.4)$ & $6.6(5.5,7.4)$ & 0.767 & $6.4(5.5,7.8)$ & $6.8(5.6,8.3)$ & 0.115 \\
\hline & 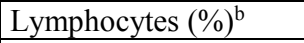 & $36.33 \pm 6.50$ & $46.50 \pm 0.70$ & $38.0 \pm 0.71$ & 0.065 & $30.0 \pm 4.24$ & $34.0 \pm 1.63$ & 0.144 \\
\hline & Neutrophlis $(\%)^{\mathrm{b}}$ & $54.4 \pm 19.76$ & $33.66 \pm 28.29$ & $58.0 \pm 28.30$ & 0.534 & $67.0 \pm 2.82$ & $62.75 \pm 1.50$ & 0.063 \\
\hline \multirow[t]{8}{*}{$\mathrm{RBC}$ indices } & $\operatorname{RBCs}\left(10^{6} / \mu \mathrm{L}\right)^{\mathrm{a}}$ & $4.9(4.5,5.3)$ & $5.2(4.9,5.5)$ & $5.2(4.9,5.4)$ & 0.844 & $4.5(4.3,4.9)$ & $4.6(4.4,4.9)$ & 0.182 \\
\hline & $\operatorname{Hgb}(\mathrm{g} / \mathrm{dl})^{\mathrm{a}}$ & $14.6(13.6,15.5)$ & $\begin{array}{l}15.5(14.9, \\
16.2)\end{array}$ & $\begin{array}{l}15.4(14.4, \\
16.1)\end{array}$ & 0.119 & $\begin{array}{l}13.6(12.9, \\
14.2)\end{array}$ & $13.7(13,14.3)$ & 0.638 \\
\hline & Hct $(\%)^{b}$ & $43(40,45.7)$ & $\begin{array}{l}45.4(43.9, \\
47.9)\end{array}$ & $\begin{array}{l}45.4(42.5 \\
48.1)\end{array}$ & 0.235 & $\begin{array}{l}39.9(38.1, \\
41.9)\end{array}$ & $40.2(37.7,42)$ & 0.990 \\
\hline & $\operatorname{MCV}(\mathrm{fL})^{\mathrm{a}}$ & $87.1(83.3,89.9)$ & $\begin{array}{l}87.8(85.1 \\
90.4)\end{array}$ & $\begin{array}{l}87.2(84, \\
89.6)\end{array}$ & 0.262 & $\begin{array}{l}87.3(82.4 \\
89.7)\end{array}$ & $\begin{array}{l}84.7(81.7 \\
88.1)\end{array}$ & 0.074 \\
\hline & $\mathrm{MCH}(\mathrm{pg})^{\mathrm{a}}$ & $29.7(28.3,30.7)$ & $\begin{array}{l}29.9(29 \\
30.9) \\
\end{array}$ & $\begin{array}{l}29.6(28.4, \\
30.4)\end{array}$ & 0.141 & $\begin{array}{l}29.5(27.6, \\
30.7)\end{array}$ & $\begin{array}{l}29.2(27.6 \\
30.4)\end{array}$ & 0.465 \\
\hline & $\mathrm{MCHC}(\mathrm{g} / \mathrm{dL})^{\mathrm{a}}$ & $34(33.3,34.6)$ & $\begin{array}{l}34(33.4 \\
34.5)\end{array}$ & $\begin{array}{l}34(33.3, \\
34.6)\end{array}$ & 0.643 & $34(33.2,34.4)$ & $\begin{array}{l}29.2(27.6 \\
30.4) \\
\end{array}$ & 0.046 \\
\hline & $\mathrm{RDW}(\mathrm{fL})^{\mathrm{a}}$ & $13.2(12.5,14.1)$ & $\begin{array}{l}13.2(12.5, \\
13.9)\end{array}$ & $\begin{array}{l}13.1(12.7, \\
13.9)\end{array}$ & 0.869 & $13.3(12.3,14)$. & \begin{tabular}{|l|}
$13.4(12.6$ \\
$14.3)$ \\
\end{tabular} & 0.340 \\
\hline & $\begin{array}{l}\text { Platelet count } \\
(103 / \mu \mathrm{L})\end{array}$ & $211(176,250)$ & $\begin{array}{l}192.5(166, \\
225.2)\end{array}$ & $\begin{array}{l}202.4(172, \\
234)\end{array}$ & 0.544 & $231(191,268)$ & $232(196,258)$ & 0.974 \\
\hline \multirow[t]{2}{*}{$\mathrm{BP}(\mathrm{mmHg})$} & Systolic BP ${ }^{b}$ & $117.8 \pm 18.7$ & $119.37 \pm 17.39$ & $120.40 \pm 18.05$ & 0.720 & $115.28 \pm 19.55$ & $116.97 \pm 20.28$ & 0.571 \\
\hline & Diastolic $\mathrm{BP}^{\mathrm{b}}$ & $75.05 \pm 12.3$ & $75.66 \pm 11.65$ & $80.0 \pm 11.62$ & 0.026 & $72.89 \pm 12.22$ & $73.55 \pm 13.70$ & 0.092 \\
\hline \multicolumn{2}{|c|}{ BMI $\left(\mathrm{Kg} / \mathrm{m}^{2}\right)^{\mathrm{b}}$} & $27.24 \pm 4.25$ & $26.15 \pm 3.70$ & $26.27 \pm 3.80$ & 0.844 & $27.93 \pm 4.48$ & $29.06 \pm 4.47$ & 0.092 \\
\hline \multicolumn{2}{|l|}{ FBS $(\mathrm{mg} / \mathrm{dl})^{b}$} & $117.72 \pm 43.82$ & $104.38 \pm 6.31$ & $147.10 \pm 71.47$ & $<0.001 *$ & $101.91 \pm 9.31$ & $149.30 \pm 65.11$ & $<0.001^{*}$ \\
\hline
\end{tabular}

a: Mann-Whitney U test median (inter quartile Rang), b: t-test (Data are given as mean \pm SD), c: Chi-Square Test, WBC: Red blood cell, RBC:

Red blood cell, BP: Blood pressure; **:p - value less than 0.05

Table 2. Correlation of hematological indices with Systolic and Diastolic BP and FBS among prediabetes and diabetes participants

\begin{tabular}{|l|l|l|l|l|l|l|}
\hline \multirow{2}{*}{ Variables } & \multicolumn{2}{|l|}{ Pre diabetes; R (p-value) } & \multicolumn{2}{l|}{ Diabetes; R (p-value) } \\
\cline { 2 - 7 } & SBP & DBP & FBS & SBP & DB & FBS \\
\hline WBC & $0.081(0.887)$ & $0.006(0.926)$ & $-0.022(0.730)$ & $0.218(0.017)^{*}$ & $0.158(0.085)$ & $0.108(0.239)$ \\
\hline Lymphocytes & $0.113(0.887)$ & $-0.513(0.487)$ & $-0.582(0.418)$ & $-0.898(0.038)^{*}$ & $-0.981(0.019)^{*}$ & $0.275(0.654)$ \\
\hline RBC & $0.078(0.213)$ & $0.057(0.361)$ & $-0.073(0.241)$ & $0.147(0.110)$ & $0.315(<0.001)^{*}$ & $-0.004(0.969)$ \\
\hline Hgb & $-0.077(0.216)$ & $-0.035(0.575)$ & $0.004(0.950)$ & $0.086(0.352)$ & $0.197(0.032)^{*}$ & $0.057(0.535)$ \\
\hline Hct & $0.096(0.123)$ & $0.10 .3(0.099)$ & $0.090(0.148)$ & $0.133(0.146)$ & $0.254(0.005)^{*}$ & $0.007(0.937)$ \\
\hline MCV & $-0.033(0.593)$ & $-0.065(0.296)$ & $0.051(0.418)$ & $-0.021(0.816)$ & $-0.064(0.488)$ & $0.010(0.915)$ \\
\hline MCH & $-0.055(0.378)$ & $-0.104(0.088)$ & $0.025(0.683)$ & $-0.071(0.442)$ & $-0.127(0.169)$ & $0.088(0.341)$ \\
\hline MCHC & $-0.041(0.329)$ & $-0.154(0.013)^{*}$ & $-0.139(0.026)^{*}$ & $-0.153(0.095)$ & $-0.195(0.033)^{*}$ & $0.200(0.028)^{*}$ \\
\hline RDW & $0.001(0.993)$ & $-0.045(0.467)$ & $-0.092(0.141)$ & $0.188(0.041)^{*}$ & $0.137(0.140)$ & $-0.085(0.358)$ \\
\hline Platelets & $-0.001(0.982)$ & $-0.053(0.399)$ & $-0.046(0.459)$ & $0.080(0.388)$ & $0.007(0.936)$ & $0.096(0.297)$ \\
\hline
\end{tabular}

R: Correlation coefficient; WBC: White blood cell; RBC: Red blood cell; Hgb: Hemoglobin; Hct: Hematocrit; MCV: Mean cell volume; MCH: Mean cell hemoglobin; MCHC: Mean cell hemoglobin concentration; RDW: Red blood distribution width

Regarding the correlation of the hematological indices with systolic BP, only the WBC count and RDW were found to be positively correlated with systolic $\mathrm{BP}(\mathrm{p}=0.017$ and $\mathrm{p}=0.041$ respectively), and only the lymphocyte count was negatively correlated with systolic BP in the T2DM group $(\mathrm{p}=0.038)$. The lymphocyte count $(\mathrm{p}=0.019), \mathrm{RBC}$ count $(\mathrm{p}<0.001)$, Hgb count $(\mathrm{p}=0.032)$, Hct count $(\mathrm{p}=0.005)$, and $\mathrm{MCHC}(\mathrm{p}=0.033)$ showed a significantly negative correlation with diastolic BP in the T2DM group. Systolic BP and the RDW showed a positive correlation in the 
diabetic group, compared with the prediabetic group. However, in the prediabetic group, only the MCHC was found to be negatively correlated with diastolic BP $(\mathrm{p}=0.013)$ and FBS $(\mathrm{p}=0.026)$ (Table 2). After adjusting for gender and sex, results did not change significantly.

\section{Discussion}

In the present study, $\mathrm{MCHC}$ was significantly higher in male diabetics than prediabetics, for other parameters (Hgb, $\mathrm{Hct}, \mathrm{MCV}$ ), there were no statistically significant difference in pre-diabetic and diabetic group in both genders. These results were not consistent with those Ezenwaka et al. (17) had reported, in which the RBC count, Hgb concentrations, and Hct levels in Caribbean patients with type 2 diabetes were lower than in the group of nondiabetic patients. In contrast to this study, another study conducted on type 2 diabetics from Northwest Ethiopia reported an increase in the RBC count and the Hgb and Hct levels, compared with the control group (9). In another study by Simmons on residents in 2,376 randomly selected households, it was shown that subjects with new diabetes and IGT/IFG had a higher RBC count than normal subjects and those with pre-existing diabetes did (11). The present study showed an elevation of the WBC count in diabetics, compared with the prediabetic group, although the difference was not statistically significant. Several other epidemiological studies have also reported an association between higher WBC and T2DM (7). In the cross-sectional study by Meisinger et al. (18) a significant association was shown between newly Detected Diabetes, known diabetes and Isolated Impaired Fasting Glucose. WBC count is a marker of systemic inflammation and $\mathrm{Du}$ et al. (19), in a prospective study concluded U-shape association between white blood cell count and the risk of diabetes in Chinese individuals. Studies by Moradi et al. on Iranian patients (20) and Tong et al. (21) on Chinese patients have also reported an association between an increase in the WBC count and the development of complications in type 2 diabetics. In the current study, we found a significant negative correlation between MCHC and systolic and diastolic BP levels in prediabetics. Although, application of MCHC to draw conclusions about the correlation between prediabetes and all hematological indices are unfounded. Qiu et al. (22), in a longitudinal population-based study, declared that subjects with both impaired glucose regulation and hypertension would be at high risk of CVD. In our study, RBC, Hgb, and $\mathrm{MCH}$ showed a significant positive correlation with diastolic BP in the group with type 2 diabetes. Furthermore, the WBC count revealed a significant positive correlation with systolic BP. In a cross-sectional study done by Shim et al. (23), a positive correlation was found to be between the total WBC count and BP. They concluded that, with an increase in the number of components of the metabolic syndrome, the total WBC count increased in type 2 diabetic patients. Moreover, a study by Chung et al. (24) on diabetics showed that the WBC count had increased in T2DM patients. They confirmed that an increase in the WBC count could cause vascular complications. We found no significant correlation between the RDW and BP in the prediabetics although there was a significant positive correlation between the RDW and systolic BP in the diabetics. Dada et al. (25), in a case-control study on 100 diabetics and 100 nondiabetics in Lagos reported a statistically significant positive correlation between the RDW and BP in the diabetics. In a study by Malandrino et al. (26), diabetics with the increased RDW had more macrovascular and microvascular complications of DM. Besides, their research suggested that the RDW might be a predictor of the onset of diabetic macrovascular complications. A high RDW indicates chronic inflammation and increased levels of oxidative stress, both of which are telltale signs in type 2 diabetics, which may significantly contribute to the development of atherosclerotic diseases $(27,28)$; Hyperglycemia, results in troubles in cellular metabolism due to enhanced generation of reactive oxygen species (ROS) and non-enzymatic glycation of many macromolecules, which lead to changes in cellular structure and function, and organization of progressive glycation end products (AGEs). The formation of AGEs enhances metabolic disturbances and also increases reactive oxygen species production via interplay with the specific receptor for AGE (RAGE); This causes changes in structure and biophysical confidents of the basement membrane which further causes changes in permeability and vasodilatation of blood vessels and may affect disease processes in target organs such as the liver, pancreas, heart, or blood vessels, and may therefore significantly contribute to chronic inflammation as T2D (29). Chronic hyperglycemia in diabetics, causes structural changes in RBC membrane proteins and reduces the negative surface electric charge, thereby leading to the accelerated aging of RBCs $(30,31)$, and, Stevens (32) argued that anemia and low Hgb concentrations led to the development of cardiovascular disease (CVD) and chronic kidney disease in diabetics. Our study had some limitations which should be considered. This was a cross-sectional study and therefore, the design was limited in its ability to eliminate causal relationships between the hematological parameters and prediabetes. No comparison was made between prediabetic and diabetic subjects and normal subjects in terms of the hematological parameters. 


\section{Conclusions}

The present observational study revealed only a statistically significant inverse correlation between the MCHC and diastolic BP among the prediabetics, compared with the diabetics. Systolic BP and diastolic BP were compared with the other hematological parameters; however, no significant correlation was observed between them. More studies with a larger sample size may help to explain changes in the hematological parameters in prediabetes since various hematological changes affecting the red blood cells (RBCs), white blood cells (WBCs), and the other hematological indices are directly related to diabetes, so hematological indices could be utile indicators of vascular complication and glycemic control in type 2 DM patients. Thus, they are important for the evaluation and early management of patients with prediabetes.

\section{Acknowledgments:}

This study was supported by a grant from the research department of Iran University of Medical Sciences. The authors would like to thank all the study participants for their voluntary participation and the department of research of Iran University of Medical Sciences for endorsing the project. Finally, we would like to thank staff members of Taban Diabetes Center for their cooperation during data collection.

\section{Conflict of Interest:}

There is no conflict of interest to be declared.

\section{Authors' contributions:}

All authors contributed to this project and article equally. All authors read and approved the final manuscript.

\section{References:}

1) Shahbazian H. World diabetes day; 2013. J Renal Inj Prev. 2013; 2(4): 123-4. doi: 10.12861/jrip.2013.39.

2) Elalamy I, Chakroun T, Gerotziafas GT, Petropoulou A, Robert F, Karroum A, et al. Circulating platelet leukocyte aggregates: a marker of microvascular injury in diabetic patients. Thromb Res. 2008; 121(6): 843-8. doi: 10.1016/j.thromres.2007.07.016. PMID: 17825880.

3) Jindal S, Gupta S, Gupta R, Kakkar A, Singh HV, Gupta K, et al. Platelet indices in diabetes mellitus: indicators of diabetic microvascular complications. Hematology. 2011; 16(2): 86-9. doi: 10.1179/102453311X12902908412110.

4) Demirtas L, Degirmenci H, Akbas EM, Ozcicek A, Timuroglu A, Gurel A, et al. Association of hematological indices with diabetes, impaired glucose regulation and microvascular complications of diabetes. Int J Clin Exp Med. 2015; 8(7): 11420-5. PMID: 26379958, PMCID: PMC4565341.

5) Meigs JB, Muller DC, Nathan DM, Blake DR, Andres R. The natural history of progression from normal glucose tolerance to type 2 diabetes in the Baltimore longitudinal study of aging. Diabetes. 2003; 52(6): 1475-84. doi: 10.2337/diabetes.52.6.1475. PMID: 12765960.

6) Levitzky YS, Pencina MJ, D’Agostino RB, Meigs JB, Murabito JM, Vasan RS, et al. Impact of Impaired Fasting Glucose on Cardiovascular Disease. J Am Coll Cardiol. 2008; 51(3): 264-70. doi: 10.1016/j.jacc.2007.09.038.

7) Cho YI, Mooney MP, Cho DJ. Hemorheological disorders in diabetes mellitus. J Diabetes Sci Technol. 2008; 2(6): 1130-8. doi: 10.1177/193229680800200622. PMID: 19885302, PMCID: PMC2769810.

8) Tamariz LJ, Young JH, Pankow JS, Yeh HC, Schmidt MI, Astor B, et al. Blood viscosity and hematocrit as risk factors for type 2 diabetes mellitus: the atherosclerosis risk in communities (ARIC) study. Am J Epidemiol. 2008; 168: 1153-60. doi: 10.1093/aje/kwn243. PMID: 18931370, PMCID: PMC2581671.

9) Biadgo B, Melku M, Abebe SM, Abebe M. Hematological indices and their correlation with fasting blood glucose level and anthropometric measurements in type 2 diabetes mellitus patients in Gondar, Northwest Ethiopia. Diabetes Metab Syndr Obes. 2016; 9: 91-9. doi: 10.2147/DMSO.S97563. PMID: 27042134, PMCID: PMC4801204.

10) Chen LK, Ming-Hsien L, Zhi-Jun C, Shinn-Jang H, Chiou ST. Association of insulin resistance and hematologic parameters: study of a middle-aged and elderly Chinese population in Taiwan. J Chin Med Assoc. 2006; 69(6): 248-53. doi: 10.1016/S1726-4901(09)70251-5. PMID: 16863009.

11) Simmons D. Increased red cell count in diabetes and pre-diabetes. Diabetes Res Clin Pract. 2010; 90(3): e50-3. doi: 10.1016/j.diabres.2010.07.005. PMID: 20701991.

12) Gokulakrishnan K, Deepa R, Sampathkumar R, Balasubramanyam M, Mohan V. Association of leukocyte count with varying degrees of glucose intolerance in Asian Indians: the Chennai Urban Rural Epidemiology Study (CURES-26). Metab Syndr Relat Disord. 2009; 7(3): 205-10. doi: 10.1089/met.2008.0024. PMID: 19284318. 
13) Coban E, Kucuktag S, Basyigit S. Platelet activation in subjects with impaired glucose tolerance. Platelets. 2007; 18: 591-4. doi: 10.1080/09537100701609019. PMID: 18041650.

14) Anuurad E, Shiwaku K, Nogi A, Kitajima K, Enkhmaa B, Shimono K, et al. The new BMI criteria for asians by the regional office for the western pacific region of WHO are suitable for screening of overweight to prevent metabolic syndrome in elder Japanese workers. J Occup Health. 2003; 45(6): 335-43. doi: 10.1539/joh.45.335. PMID: 14676412.

15) American Diabetes Association. Diagnosis and Classification of Diabetes Mellitus. Diabetes Care. 2010; 33(Suppl 1): S62-9. doi: 10.2337/dc10-S062. PMID: 20042775, PMCID: PMC2797383.

16) Tan BT, Nava AJ, George TI. Evaluation of the Beckman Coulter UniCel DxH 800, Beckman Coulter LH 780, and Abbott Diagnostics Cell-Dyn Sapphire hematology analyzers on adult specimens in a tertiary care hospital. Am J Clin Pathol. 2011; 135: 939-51. doi: 10.1309/AJCP1V3UXEIQTSLE. PMID: 21571967.

17) Ezenwaka CE, Jones-Lecointe A, Nwagbara E, Seales D, Okali F. Anemia and kidney dysfunction in Caribbean type 2 diabetic patients. Cardiovasc Diabetol. 2008; 7: 25. doi: 10.1186/1475-2840-7-25.

18) Meisinger C, Rückert IM, Stöckl D, Thorand B, Peters A, Kowall B, et al. Hematological Parameters and Prediabetes and Diabetes in Adults from the General Population: A Cross-Sectional Study. J Diabetes Metab. 2014; 5: 2. doi: 10.4172/2155-6156.1000335.

19) Du X, Zhu B, Hu G, Mao W, Wang S, Zhang H, et al. U-shape association between white blood cell count and the risk of diabetes in young Chinese adults. Diabet Med. 2009; 26(10): 955-60. doi: 10.1111/j.14645491.2009.02801.x. PMID: 19900225.

20) Moradi S, Kerman SR, Rohani F, Salari F. Association between diabetes complications and leukocyte counts in Iranian patients. J Inflamm Res. 2012; 5: 7-11. doi: 10.2147/JIR.S26917. PMID: 22334791, PMCID: PMC3278259.

21) Tong PC, Lee KF, So WY, Ng MH, Chan WB, Lo MK, et al. White blood cell count is associated with macro- and microvascular complications in chinese patients with type 2 diabetes. Diabetes Care. 2004; 27(1): 216-22. doi: 10.2337/diacare.27.1.216. PMID: 14693992.

22) Qiu M, Shen W, Song X, Ju L, Tong W, Wang H, et al. Effects of prediabetes mellitus alone or plus hypertension on subsequent occurrence of cardiovascular disease and diabetes mellitus: longitudinal study. Hypertension. 2015; 65(3): 525-30. doi: 10.1161/HYPERTENSIONAHA.114.04632. PMID: 25624343.

23) Shim WS, Kim HJ, Kang ES, Ahn CW, Lim SK, Lee HC, et al. The association of total and differential white blood cell count with metabolic syndrome in type 2diabetic patients. Diabetes Res Clin Pract. 2006; 73(3): 284-91. doi: 10.1016/j.diabres.2006.02.001. PMID: 16563549.

24) Chung FM, Tsai JC, Chang DM, Shin SJ, Lee YJ. Peripheral total and differential leukocyte count in diabetic nephropathy: the relationship of plasma leptin to leukocytosis. Diabetes Care. 2005; 28(7): 1710-7. doi: 10.2337/diacare.28.7.1710. PMID: 15983324.

25) Dada OA, Uche E, Akinbami A, Odesanya M, John-Olabode S, Adediran A, et al. The relationship between red blood cell distribution width and blood pressure in patients with type 2 diabetes mellitus in Lagos, Nigeria. J Blood Med. 2014; 5: 185-9. doi: 10.2147/JBM.S67989.

26) Malandrino $\mathrm{N}, \mathrm{Wu}$ WC, Taveira TH, Whitlatch HB, Smith RJ. Association between red blood cell distribution width and macrovascular and microvascular complications in diabetes. Diabetologia. 2012; 55(1): 226-35. doi: 10.1007/s00125-011-2331-1.

27) Tesfamariam B, Cohen RA. Free radicals mediate endothelial cell dysfunction caused by elevated glucose. Am J Physiol. 1992; 263(2 Pt 2): H321-6. PMID: 1510128.

28) King GL, Loeken MR. Hyperglycemia-induced oxidative stress in diabetic complications. Histochem Cell Biol. 2004; 122(4): 333-8. doi: 10.1007/s00418-004-0678-9.

29) Gerner RR, Wieser V, Moschen AR, Tilg H. Metabolic inflammation: role of cytokines in the crosstalk between adipose tissue and liver. Can J Physiol Pharmacol. 2013; 91(11): 867-72. doi: 10.1139/cjpp-20130050. PMID: 24117253.

30) Cawood TJ, Buckley U, Murray A, Corbett M, Dillon D, Goodwin B, et al. Prevalence of anaemia in patients with diabetes mellitus. Ir J Med Sci. 2006; 175(2): 25-7. doi: 10.1007/BF03167944. PMID: 16872024.

31) Wang ZS, Song ZC, Bai JH, Li F, Wu T, Qi J, et al. Red blood cell count as an indicator of microvascular complications in Chinese patients with type 2 diabetes mellitus. Vasc Health Risk Manag. 2013; 9: $237-43$. doi: 10.2147/VHRM.S43211. PMID: 23690689, PMCID: PMC3656917.

32) Stevens PE. Anaemia, diabetes and chronic kidney disease: where are we now? J Ren Care. $2012 ; 38$ Suppl 1: 67-77. doi: 10.1111/j.1755-6686.2012.00281.x. 